\title{
Of mice and men: on the origin of XMRV
}

\section{Antoinette Cornelia van der Kuyl, Marion Cornelissen and Ben Berkhout*}

Laboratory of Experimental Virology, Department of Medical Microbiology, Center for Infection and Immunity Amsterdam, Academic Medical Center, University of Amsterdam, Amsterdam, Netherlands

\section{Edited by:}

Antti Vaheri, University of Helsinki,

Finland

\section{Reviewed by:}

Jonas Blomberg, Uppsala University and Uppsala Academic Hospital,

Sweden

Nicole Fischer, University Medical Center Hamburg-Eppendorf, Germany

*Correspondence:

Ben Berkhout, Laboratory of Experimental Medicine, Department of Medical Microbiology, Academic Medical Center, Meibergdreef 15, 1105 AZ Amsterdam, Netherlands. e-mail:b.berkhout@amc.uva.nl

The novel human retrovirus xenotropic murine leukemia virus-related virus (XMRV) is arguably the most controversial virus of this moment. After its original discovery in prostate cancer tissue from North American patients, it was subsequently detected in individuals with chronic fatigue syndrome from the same continent. However, most other research groups, mainly from Europe, reported negative results. The positive results could possibly be attributed to contamination with mouse products in a number of cases, as XMRV is nearly identical in nucleotide sequence to endogenous retroviruses in the mouse genome. But the detection of integrated XMRV proviruses in prostate cancer tissue proves it to be a genuine virus that replicates in human cells, leaving the question: how did XMRV enter the human population? We will discuss two possible routes: either via direct virus transmission from mouse to human, as repeatedly seen for, e.g., Hantaviruses, or via the use of mouse-related products by humans, including vaccines. We hypothesize that mouse cells or human cell lines used for vaccine production could have been contaminated with a replicating variant of the XMRV precursors encoded by the mouse genome.

\section{Keywords: XMRV, mouse, retrovirus, vaccine, transmission}

\section{INTRODUCTION}

The xenotropic murine leukemia virus-related virus (XMRV) is undoubtedly the most controversial human virus since its first detection in human samples in 2006 (Urisman et al., 2006). XMRV infection still lacks a firm disease association, although the virus was originally isolated from prostate cancer tissue and subsequently detected in the blood of American patients with chronic fatigue syndrome (CFS; Lombardi et al., 2009), and in the respiratory tract of patients with or without a respiratory tract infection (Fischer et al., 2010). However, irregular XMRV detection (Fischer et al., 2008, 2010; Lombardi et al., 2009; Groom et al., 2010; Switzer et al., 2010; van Kuppeveld et al., 2010) suggests that it is not likely to be a major causal factor. First, we do not know whether the biological reservoir has been investigated thus far, as most studies focused exclusively on blood or prostate tissue (summarized in Table 1). Second, some pathogenic retroviruses do not cause much of a viremia, and experimental infection of macaques suggests that this is also the case for XMRV (Sharma et al., 2010). In these monkeys, virus inoculation resulted in a low transient plasma viremia, followed by a wide dissemination of replicating virus into various organs including spleen, lymph nodes, and gastrointestinal tract. Third, sequence variation may exist, but such variant virus strains could be missed by the PCR primers used.

Whether or not the virus causes disease in humans (reviewed extensively by Silverman et al., 2010, see also comments by Coffin and Stoye, 2009, by Kearney and Maldarelli, 2010, by Kaiser, 2010, and the cautionary note by Weiss, 2010), and how and when XMRV entered the human population - as the first Gammaretrovirus to do so - remains unclear. To add to the ongoing discussion, we would like to propose an alternative possible source for XMRV, human vaccines or other biological products that were produced in murine cells.

\section{HOW DID XMRV ENTER THE HUMAN POPULATION?}

One of the most striking aspects of XMRV biology is the high sequence similarity to mouse chromosomal sequences that encode endogenous retroviruses. Initially, this raised the speculation that contamination with mouse DNA could explain the presence of $\mathrm{XMRV}$ in human samples. However, the absence of other mousederived sequences, combined with the ease of infection of human cells with XMRV in vitro (Stieler et al., 2010), and the detection of integrated proviruses in prostate cancer tissues (Dong et al., 2007; Kim et al., 2008) indicated that laboratory contamination with mouse products is not a likely explanation for the origin of XMRV, at least for some of these studies. If contamination does not provide an explanation, where does the virus come from and how did it end up in humans?

Direct transmission of viruses from wild rodents to humans is not uncommon, e.g., rodent Hantaviruses and Arenaviruses spread through excrement via aerosols and are able to infect non-rodent species, including humans (Hart and Bennett, 1999; Klein and Calisher, 2007; Charrel and de Lamballerie, 2010). Transmission of xenotropic murine leukemia viruses (X-MLV's) to humans is possible as human cells do express the XPR1 protein that is able to function as receptor for xenotropic and polytropic murine retroviruses. The human XPR1 receptor protein shows a preference for xenotropic retroviruses, but is also able to mediate infection of polytropic murine leukemia retroviruses (P-MLV's; Tailor et al., 1999). Classical laboratory mice strains are hybrids between Mus musculus musculus, M. m. domesticus and M. m. castaneus, with around two-thirds of the genome coming from $M$. $m$. domesticus (Yang et al., 2007). X-MLV's cannot (re-)infect most of the laboratory mouse strains due to polymorphisms in the XPR1 protein that disable xenotropic virus entry (Marin et al., 1999). Interestingly, the XPR1 genotype that prohibits X-MLV entry was not found 
Table 1 | XMRV prevalence and geography.

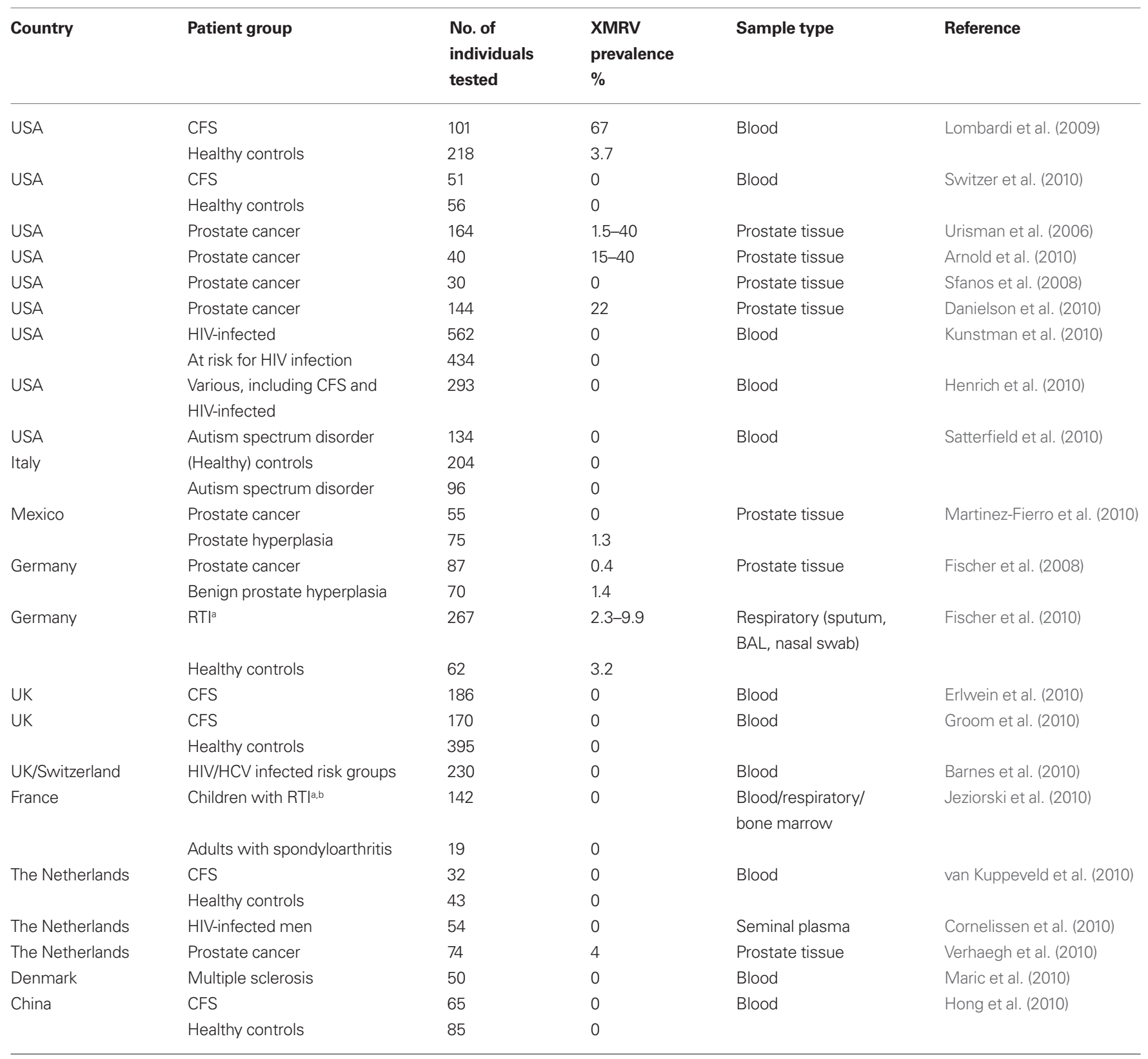

${ }^{a}$ Respiratory tract infection.

${ }^{b}$ Other hematological, neurological, or inflammatory pathologies.

in wild-caught $M . m$. domesticus, suggesting that it is a rare allele (Baliji et al., 2010). Indeed, extensive screening identified seven strains of laboratory mice strains containing a permissive allele, of which at least three were susceptible to X-MLV and XMRV in cell culture (Baliji et al., 2010). In addition, the F/St mouse strain also produced infectious X-MLV together with a life-long viremia (Baliji et al., 2010). Many feral mice species, e.g., M. dunni and M. spretus, are also susceptible to infection with X-MLV's (Battini et al., 1999; Marin et al., 1999; Tailor et al., 1999). Evidence on M. m. castaneus is conflicting, with some reporting a non-functional and others a susceptible XPR1 phenotype (Marin et al., 1999; Yan et al., 2010).
The ability of XPR1 to function as a receptor for xenotropic viruses was found to depend on the identity of two amino acid residues (Marin et al., 1999).

\section{THE ORIGIN OF XMRV?}

Every mouse genome contains multiple copies of endogenous MLV and has thus the capacity to express viral RNA and possibly viral particles. Endogenous MLV transcription has been described for many tissues and several mouse strains. It remains unclear if and when virus particles are generated and whether these particles are actually excreted. Zoonotic transmission of these viruses 
could have occurred in the many million years that mice and men have shared the same environment. But current XMRV sequences isolated from human samples do closely mimic mouse genomic sequences, thus suggesting a low number of replication cycles since zoonotic transmission, which is thus likely to have occurred recently. The mutation rate of MLV's is not different from other retroviruses (Sanjuan et al., 2010; although its replication rate may be low), implying that if the transmission had taken place a long time ago, more nucleotide substitutions should have become fixed. Phylogenetic sequence analysis, however, revealed very short branches for XMRV and the mouse XMERV sequences on chromosomes 7 and 9, indicating that very few mutations have occurred since transmission (Urisman et al., 2006; Fischer et al., 2008, 2010). In addition to the loci on chromosomes 7 and 9, a BLAST search using the NCBI sequence database ${ }^{1}$ retrieves loci on mouse chromosomes 4,11 , and 12 with a much higher (98-100\%) sequence identity to XMRV-gag nucleotide sequences (e.g., GenBank accession numbers AC124739, AY349138, and AL627314). Blasting whole genome XMRV sequences recovers very similar sequences with large stretches of sequence identity on mouse chromosomes 4 , 5,13 , and $Y$, especially for the $3^{\prime}$ end of the XMRV genome. These results suggest that the genome of human XMRV is present, albeit in two parts, in the mouse genome with effectively no nucleotide changes. Even in slowly evolving retroviruses like foamy viruses, $100 \%$ sequence identity is only seen in animals with close contact or humans that have been bitten by an infected primate, suggestive of direct transmission, while intraspecies variation is generally around $85-95 \%$ for the pol gene (Switzer et al., 2004; Calattini et al., 2006; Liu et al., 2008).

A recently described locus (Baliji et al., 2010) on chromosome 1 of M. musculus (GenBank accession number AC115959) contains a provirus that is $92 \%$ homologous to XMRV from the $22 \mathrm{Rv} 1$ cell line (GenBank accession number FN692043) over its complete genome length. This provirus, Bxv1, is mainly found in Japanese M. molossinus (a natural hybrid of M. castaneus and M. musculus) and is highly expressed in some laboratory mouse strains (Baliji et al., 2010). However, the Bxv1 provirus is less likely to be the source of XMRV, as its similarity to XMRV is much lower than that of other murine loci.

\section{XMRV IS A NOVEL RECOMBINANT RETROVIRUS}

Xenotropic murine leukemia virus-related virus is actually a recombinant virus, resembling polytropic-endogenous sequences for the $5^{\prime}$ half up to approximately the middle of the pol gene and xenotropic-endogenous sequences for the $3^{\prime}$ half of the genome, which includes the env gene (see: Courgnaud et al., 2010). This recombination event is likely to have occurred in the mouse before transmission to humans. At least one recombinant provirus, Bxv1, is already found in the M. musculus genome (Baliji et al., 2010). This locus is heterogeneous in subspecies of M. musculus, suggesting that it represents a recent integration. Recombination rates are high for all retroviruses because they package two copies of the RNA genome in virions, which drives subsequent mixing of sequences during the reverse transcription process. Recombination also enables the generation of replication-competent viruses from

${ }^{1}$ http://blast.ncbi.nlm.nih.gov/Blast.cgi defective endogenous proviruses. Recombination can also extend the viral host range (cell type and/or host species). A virus carrying a xenotropic env gene is more infectious for human cells as the human XPR1 protein has a preference for xenotropic murine envelope proteins over polytropic ones. The replication-competent endogenous cat retrovirus RD-114 is an example of a recombinant virus expressed from endogenous sequences. It combines FcEV gagpol genes (FcEV is an endogenous retrovirus of cats) and a BaEV env gene ( $\mathrm{BaEV}$ is an endogenous retrovirus of African monkeys) (van der Kuyl et al., 1999). RD-114 is expressed by all species of the genus Felis, but not in other felines, and probably originates from a cross-species transmission of $\mathrm{BaEV}$, followed by a recombination event and subsequent germ-line integration.

\section{ARE MOUSE-DERIVED BIOLOGICAL PRODUCTS THE SOURCE OF XMRV?}

Detection rates of XMRV in populations are extremely variable, with $0-67 \%$ positivity in patients and $0-3.7 \%$ in healthy controls (Fischer et al., 2008, 2010; Lombardi et al., 2009; Groom et al., 2010; Switzer et al., 2010; van Kuppeveld et al., 2010), suggesting that virus prevalence and thus exposure could vary significantly with geographic location. Although the virus could possibly be transmitted from feral mice to humans in a natural setting, followed by a rapid dissemination in the human population, the high XMRV sequence similarity on two continents would suggest an alternative transmission route. Likely sources of XMRV are mouse-derived products. Some mouse genomes encode complete copies of X-MLV's with at least $92 \%$ similarity to $\mathrm{XMRV}$; segments with even higher homology are present on other locations, and could result in novel recombinant viruses. So, X-MLV's that closely resemble XMRV could then be produced from these loci and virions could be excreted from mouse tissue or cell cultures.

\section{ARE X-MLV's PRODUCED IN MICE?}

MLV's, including xenotropic sequences, are actively transcribed in mouse brain (Kwon et al., 2008), and mice can produce virus particles of different MLV classes (Ribet et al., 2008). In vivo recombination between endogenous and exogenous polytropic MLV's has also been reported, resulting in viable viral offspring capable of infecting a variety of species (Evans et al., 2009). The Bxv1 locus in M. musculus molossinus is an example of an endogenous xenotropic/polytropic recombinant MLV that is expressed and gives rise to a life-long viremia in laboratory mice of the F/St strain (Baliji et al., 2010).

Although there was no evidence of X-MLV transmission to human embryonic stem cells expressing XPR1 after cocultivation with murine cells expressing X-MLV particles in a single report (Amit et al., 2005), this does not imply that transmission may not have occurred on another occasion. The prostate carcinoma cell line $22 \mathrm{Rv} 1$ is a popular research tool because it contains approximately 10 integrated copies of the XMRV provirus and it produces infectious virus (Knouf et al., 2009). The origin of the $22 \mathrm{Rv} 1$ cell line may represent a recent transmission case as a carcinoma was grafted in nude mice to establish this permanent cell line (Sramkoski et al., 1999). The complete $22 \mathrm{Rv} 1$ provirus has $99 \%$ sequence similarity with other XMRV isolates (Paprotka et al., 2010). Possibly, the 22Rv1 carcinoma cells were infected with XMRV by mouse cells surrounding the tumor graft (Knouf et al., 2009). 


\section{VACCINES, VIRUSES, AND CONTAMINATION}

One of the most widely distributed biological products that frequently involved mice or mouse tissue, at least up to recent years, are vaccines, especially vaccines against viruses. Some, for instance vaccines against rabies virus (Plotkin and Wiktor, 1978), yellow fever (YF) virus (Frierson, 2010), and Japanese encephalitis (JE) virus (Inactivated Japanese Encephalitis Virus Vaccine, 1993), consisted of viruses that were cultured on mouse brains. Such vaccines were in use from 1931 (YF vaccine) until now (JE vaccine, licensed in Japan since 1954). For rabies virus, early vaccines were mainly of goat or sheep nerve tissue origin. In addition, suckling mouse brain-derived rabies virus vaccines were used in South America and France (Plotkin and Wiktor, 1978). No mouse-derived rabies vaccine was ever licensed in the USA (Dennehy, 2001). Live-attenuated YF vaccines were originally also grown on mouse brain, but an YF vaccine grown on chicken eggs (named 17D) became available in 1937, and was since the vaccine of choice in the America's. In 1962, contamination of the 17D vaccine with oncogenic avian leukosis virus was detected both in England and in the USA, but fortunately no excess of cancer incidence among vaccines was reported (Frierson, 2010). In France, the mouse brain-derived YF vaccine was discontinued as late as 1982 .

Although being the most effective means to prevent infectious diseases and to safe lives, serious contamination problems involving vaccines have occurred (Pastoret, 2010). Contamination with unrelated viruses such as the presence of hepatitis $B$ virus (HBV) in YF vaccine preparations stemming from the use of human serum for stabilization, and simian virus 40 (SV40) and foamy viruses through the use of monkey cell cultures (Pastoret, 2010). Some vaccine viruses are inactivated before use, hopefully also inactivating any contaminating virus particles, but the contaminating virus may be more stable than the vaccine virus. For instance, SV40 is highly resistant to inactivation (Murray, 1964). Endogenous retroviruses constitute a distinct class of contaminating viruses, as these viruses are encoded by all cells of a certain species, and therefore cannot be avoided even through rigorous screening (Miyazawa, 2010). Contamination with endogenous avian leukosis viruses is a major problem for vaccine viruses grown in chicken embryos or chicken embryonic fibroblasts (Hussain et al., 2003). Infectious cat endogenous RD-114 virus has been found in several veterinary vaccines produced in cat cell cultures (Miyazawa et al., 2010; Yoshikawa et al., 2010).

\section{XMRV AND MONOCLONAL ANTIBODIES}

Apart from vaccines, other mouse-derived biologicals could have been a source of XMRV in the human population. Monoclonal antibodies present a modern treatment for many cancers and other diseases including cardiovascular disease, psoriasis, and auto-immune disorders (for a review see: Stern and Herrmann, 2005). The first monoclonal antibody, OKT3 (to be used against transplant rejection), was approved by the FDA in 1986. The market for monoclonal antibody therapy has been expanding rapidly after the year 2000 . Initially, murine antibodies produced by the hybridoma technique were used (Kohler and Milstein, 1975), but these have been largely abandoned because of (sometimes severe) allergic reactions. The murine antibodies were often replaced by humanized antibodies mainly produced in transgenic mice. Monoclonal antibodies generated in mice could possibly be polluted by XMRV and related viruses. Platinum Taq polymerase from Invitrogen Corporation, prepared using mouse monoclonal antibodies, is known to be frequently contaminated with mouse DNA, which can generate falsepositive PCR amplifications in combination with X-MLV or XMRV primers (Erlwein et al., 2010a). It is less likely that monoclonal antibodies from mice are a major source of XMRV in the human population as they are in use only recently, but they could provide a future supply of mouse-derived viruses. Although monoclonals are treated with detergents before use in patients, virus inactivation may not be complete, especially as protein function should be conserved. And if retroviral particles containing RNA genomes are copurified with the antibody proteins, the absence of mouse DNA may give a false impression of safety.

\section{XMRV CONTAMINATION OF CELL LINES?}

It is possible that XMRV particles were present in virus stocks cultured in mice or mouse cells for vaccine production, and that the virus was transferred to the human population by vaccination. The sequence homogeneity of all XMRV isolates known today suggests that only a single or very few transmissions have occurred, which is consistent with the proposed vaccination route. Nowadays, vaccine batches are carefully checked with sensitive PCR assays for the presence of contaminating retroviruses, but this screening was not performed in the early years of vaccination (Trijzelaar, 1993 see also Miyazawa et al., 2010). Apart from vaccines, other biological products have been generated using mice or mouse cells. Alternatively, laboratory contamination with a mouse-derived virus of cell lines used for, e.g., vaccine production could have occurred (Hartley et al., 2008; Takeuchi et al., 2008; Stang et al., 2009). The virus could then unintentionally have been transmitted to the human population. Nowadays, many vaccine strains are grown in human diploid cell lines (Fletcher et al., 1998), which are susceptible to MLV infection. A recent report detected other MLV-related sequences in CFS patients and healthy controls from North America (Lo et al., 2010), suggesting that more MLV strains may have been transmitted to the human population, possibly in a similar fashion. However, solid evidence that these polytropic MLV sequences represent replicating virus is currently lacking.

\section{WHERE WAS XMRV TRANSMITTED?}

Xenotropic murine leukemia virus-related virus was found in samples from CFS patients in North America, but not in Europe. The virus was detected in prostate cancer tissue from patients on both continents. There is a single report with negative results from China (Hong et al., 2010), and a single report with one positive sample from Mexico (Martinez-Fierro et al., 2010) but none from other areas of the world, leaving many questions about the true distribution of XMRV in humans. Prevalence of XMRV from North American studies varies between 3.7 and $67 \%$ in four studies with two other studies reporting negative results (one in CFS patients and healthy controls (Switzer et al., 2010), and one in HIVinfected patients receiving antiretroviral therapy and untreated men at risk for HIV infection (Kunstman et al., 2010)). In Europe, XMRV was detected in two studies from Germany (Fischer et al., 2010), and in one from The Netherlands (Verhaegh et al., 2010), 
but not in the UK (Erlwein et al., 2010b; Groom et al., 2010), France (Jeziorski et al., 2010), Denmark (Maric et al., 2010), and two other studies from The Netherlands (Cornelissen et al., 2010; van Kuppeveld et al., 2010), although the nature of the samples analyzed differed between studies. Table 1 summarizes the results from these studies.

Xenotropic murine leukemia virus-related virus sequences from Germany and North America exhibit very little nucleotide divergence, suggesting that they descended from a common ancestor relatively recently. A close inspection of the phylogenetic trees obtained with XMRV-gag sequences (Fischer et al., 2008, 2010) suggests that XMRV sequences from the USA are closer to the common ancestor than German XMRV sequences, although the trees are not optimal due to the high sequence conservation. Being closer to the most recent common ancestor (MRCA) is suggestive of an older virus. Possibly, XMRV was transmitted from mice to men in the USA, and soon after this event introduced into Germany. Germany had close connections with the USA after World War II, with large numbers of military personnel (and their families) stationed in Germany from 1945 till present times. In 2006, there were still 57.080 American army employees distributed over more than 200 locations in Germany, mainly in the south and west of the country ${ }^{2}$. US military personnel are highly vaccinated, e.g., virtually all recruits were vaccinated with YF vaccine in 1941-1942 after the outbreak of World War II (Frierson, 2010). A massive outbreak of jaundice, with at least 26,000 cases in the Western region of the USA, was due to the use of human serum contaminated with HBV in the vaccine (see Frierson, 2010). Recently, massive smallpox vaccination of the US army personnel has been carried out (Grabenstein and Winkenwerder, 2003). XMRV-infected Americans could subsequently have introduced the virus into Germany.

\section{SPREAD OF XMRV}

The combined results suggest (1) that XMRV was recently transmitted from mice to humans, either from a single source, or at least from a single (sub) species of mice, and (2) that all XMRV-positive individuals known today were infected with this newly emerged virus only recently, as a very high sequence identity is normally only seen after a direct retrovirus transmission.

Whatever the mechanism of XMRV cross-species transmission from mouse in humans, the possible spread from human to human forms a major health threat. Sexual transmission

${ }^{2}$ www.defense.gov/pubs/BSR_2007_Baseline.pdf

\section{REFERENCES}

Amit, M., Winkler, M. E., Menke, S., Bruning, E., Buscher, K., Denner, J., Haverich, A., Itskovitz-Eldor, J., and Martin, U. (2005). No evidence for infection of human embryonic stem cells by feeder cell-derived murine leukemia viruses. Stem Cells 23, 761-771.

Arnold, R. S., Makarova, N. V., Osunkoya, A. O., Suppiah, S., Scott,
T. A., Johnson, N. A., Bhosle, S. M., Liotta, D., Hunter, E., Marshall, F. F., Ly, H., Molinaro, R. J., Blackwell, J. L., and Petros, J. A. (2010). XMRV infection in patients with prostate cancer: novel serologic assay and correlation with PCR and FISH. Urology 75, 755-761.

Baliji, S., Liu, Q., and Kozak, C. A. (2010). Commoninbredstrains of thelaboratory mouse that are susceptible to infection by

was initially proposed (Hong et al., 2009), but XMRV was not detected in seminal plasma from HIV-infected men (Cornelissen et al., 2010). The detection of XMRV fragments in the respiratory tract (Fischer et al., 2010) suggests that the virus may be transmitted by saliva, although RNA concentrations were low. Transmission through saliva, mainly by biting, has been reported for most retrovirus genera, including ecotropic MLV's (Portis et al., 1987). Another major threat is transmission through blood products as infectious virus has been cultured from blood cells (Lombardi et al., 2009).

Up till now, all patients with detectable XMRV have been adults, the majority of them middle-aged or older (mean \pm 55 years). A study in 142 children with a diversity of pathologies, including respiratory diseases in France revealed no XMRV infections in that age group (Jeziorski et al., 2010), although the incidence of XMRV in France is not known. Another study in autistic children from the USA and Italy was also negative for XMRV (Satterfield et al., 2010). XMRV can likely be acquired at any age, and then probably establishes a chronic, latent infection like other retroviruses. Therefore the age of XMRV-infected individuals does not provide an unambiguous clue about when XMRV entered the human population.

\section{CONCLUSION}

In conclusion, the most likely mode of XMRV transmission points to mouse-derived biological products, but it cannot formally be excluded that the virus was once transferred from feral mice to humans. The latter scenario is less likely as it would imply that a very rapid spread in the human population must have occurred to explain its presence on two continents. In this scenario, the extreme sequence similarity among XMRV genomes, both between and within individuals, would argue that the virus replicates at very low levels. Among the biological products, vaccines that were produced in mice or mouse cells are possible candidates that warrant further inspection. If XMRV was introduced in the human population through the use of biologicals, a background level of the virus in the human population, possibly varying with geography or age group, would be expected. Such a low level presence would then also explain the (absence of) detection of the virus in different studies, as well as its controversial association with disease.

We hope that this hypothesis will spur further discussion and help to resolve the many remaining XMRV questions.

\section{ACKNOWLEDGMENT}

We thank Hans Zaaijer for insightful discussions and proofreading of the manuscript.

mouse xenotropic Gammaretroviruses and the human derived XMRV. J. Virol. 84, 12841-12849.

Barnes, E., Flanagan, P., Brown, A., Robinson, N., Brown, H., McClure, M., Oxenius, A., Collier, J., Weber, J., Günthard, H. F., Hirschel, B., Fidler S., Phillips, R., and Frater, J. (2010). Failure to detect xenotropic murine leukemia virus related virus in blood of individuals at high risk of blood borne viral infections. J. Infect. Dis. 202, 1482-1485

Battini, J. L., Rasko, J. E., and Miller, A. D. (1999).A human cell-surface receptor for xenotropic and polytropic murine leukemia viruses: possible role in $\mathrm{G}$ protein-coupled signal transduction. Proc Natl. Acad. Sci. U.S.A. 96, 1385-1390.

Calattini, S., Wanert, F., Thierry, B., Schmitt, C., Bassot, S., Saib, A., Herrenschmidt, 
N., and Gessain, A. (2006). Modes of transmission and genetic diversity of foamy viruses in a Macaca tonkeana colony. Retrovirology 3, 23.

Charrel, R.N., and deLamballerie,X. (2010). Zoonotic aspects of Arenavirus infections. Vet. Microbiol. 140, 213-220.

Coffin, J. M., and Stoye, J. P. (2009). Virology. A new virus for old diseases? Science 326, 530-531.

Cornelissen, M., Zorgdrager, F., Blom, P., Jurriaans, S., Repping, S., van, L. E., Bakker, M., Berkhout, B., and van der Kuyl,A.C. (2010). Lack of detection of XMRV in seminal plasma from HIV-1 infected men in The Netherlands. PLoS ONE, 5, e12040. doi: 10.1371/ journal.pone.0012040

Courgnaud, V., Battini, J. L., Sitbon, M., and Mason, A. L. (2010). Mouse retroviruses and chronic fatigue syndrome: does X (or P) mark the spot? Proc. Natl. Acad. Sci. U.S.A. 107, 15666-15667.

Danielson, B. P., Ayala, G. E., and Kimata, J. T. (2010). Detection of xenotropic murine leukemia virus related virus in normal and tumor tissue of patients from the Southern United States with prostate cancer is dependent on specific polymerase chain reaction conditions. J. Infect. Dis. 202, 1470-1477.

Dennehy, P. H. (2001). Active immunization in the United States: developments over the past decade. Clin. Microbiol. Rev. 14, 872-908.

Dong, B., Kim, S., Hong, S., Das, G. J., Malathi, K., Klein, E. A., Ganem, D., DeRisi, J. L., Chow, S. A., and Silverman, R.H. (2007). An infectious retrovirus susceptible to an IFN antiviral pathway from human prostate tumors. Proc. Natl. Acad. Sci. U. S. A. 104, 1655-1660.

Erlwein, O., Kaye, S., Robinson, M., and McClure, M. (2010a). Chronic fatigue syndrome: xenotropic murine leukemia virus-related virus, murine leukemia virus, both, or neither? Proc. Natl. Acad. Sci. U.S.A. 107, E161.

Erlwein, O., Kaye, S., McClure, M. O., Weber, J., Wills, G., Collier, D., Wessely, S., and Cleare, A. (2010b). Failure to detect the novel retrovirus XMRV in chronic fatigue syndrome. PLoS ONE 5, e8519. doi: 10.1371/journal. pone.0008519

Evans, L. H., Alamgir, A. S., Owens, N., Weber, N., Virtaneva, K., Barbian, K., Babar, A., Malik, F., and Rosenke, K. (2009). Mobilization of endogenous retroviruses in mice after infection with an exogenous retrovirus. J. Virol. 83, 2429-2435.

Fischer, N., Hellwinkel, O., Schulz, C., Chun, F. K., Huland, H., Aepfelbacher, M., and Schlomm, T. (2008).Prevalence of human Gammaretrovirus XMRV in sporadic prostate cancer. J. Clin. Virol. 43, 277-283.
Fischer, N., Schulz, C., Stieler, K., Hohn, O., Lange, C., Drosten, C., and Aepfelbacher, M. (2010). Xenotropic murine leukemia virus-related Gammaretrovirus in respiratory tract. Emerging Infect. Dis. 16, 1000-1002.

Fletcher, M. A., Hessel, L., and Plotkin, S. A. (1998). Human diploid cell strains (HDCS) viral vaccines. Dev. Biol. Stand. 93, 97-107.

Frierson, J. G. (2010). The yellow fever vaccine: a history. Yale J. Biol. Med. $83,77-85$.

Grabenstein, J. D., and Winkenwerder, W. Jr. (2003). US military smallpox vaccination program experience. JAMA 289, 3278-3282.

Groom, H. C., Yap, M. W., Galao, R. P., Neil, S. J., and Bishop, K. N. (2010). Susceptibility of xenotropic murine leukemia virus-related virus (XMRV) to retroviral restriction factors. Proc. Natl. Acad. Sci. U.S.A. 107, 5166-5177.

Hart, C. A., and Bennett, M. (1999). Hantavirus infections: epidemiology and pathogenesis. Microbes Infect. 1, 1229-1237.

Hartley, J. W., Evans, L. H., Green, K. Y., Naghashfar, Z., Macias, A. R., Zerfas, P. M., and Ward, J.M. (2008). Expression of infectious murine leukemia viruses by RAW264.7 cells, a potential complication for studies with a widely used mouse macrophage cell line. Retrovirology 5, 1.

Henrich, T. J., Li, J. Z., Felsenstein, D., Kotton, C. N., Plenge, R. M., Pereyra, F., Marty, F. M., Lin, N. H., Grazioso, P., Crochiere, D. M., Eggers, D., Kuritzkes, D. R., and Tsibris, A. M. N. (2010). Xenotropic murine leukemia virus related virus prevalence in patients with chronic fatigue syndrome or chronic immunomodulatory conditions. J. Infect. Dis. 202, 1478-1481.

Hong, P., Li, J., and Li, Y. (2010). Failure to detect xenotropic murine leukaemia virus-related virus in Chinese patients with chronic fatigue syndrome. Virol. J. 7, 224.

Hong, S., Klein, E. A., Das, G. J., Hanke, K., Weight, C. J., Nguyen, C., Gaughan, C., Kim, K. A., Bannert, N., Kirchhoff, F., Munch, J., and Silverman, R. H. (2009). Fibrils of prostatic acid phosphatase fragments boost infections with XMRV (xenotropic murine leukemia virus-related virus), a human retrovirus associated with prostate cancer. J. Virol. 83, 6995-7003.

Hussain, A. I., Johnson, J.A., Da Silva, F. M., and Heneine, W. (2003). Identification and characterization of avian retroviruses in chicken embryo-derived yellow fever vaccines: investigation of transmission to vaccine recipients. $J$. Virol. 77, 1105-1111.

Inactivated Japanese Encephalitis Virus Vaccine. (1993). Recommendations of the Advisory Committee on Immunization Practices (ACIP). MMWR Recomm. Rep. 42, 1-15.

Jeziorski, E., Foulongne, V., Ludwig, C., Louhaem, D., Chiocchia, G., Segondy, M., Rodiere, M., Sitbon, M., and Courgnaud, V. (2010). No evidence for XMRV association in pediatric idiopathic diseases in France. Retrovirology 7,63 .

Kaiser, J. (2010). Virology. No meeting of minds on XMRV's role in chronic fatigue, cancer. Science 329, 1454.

Kearney, M., and Maldarelli, F. (2010). Current status of xenotropic murine leukemia virus-related retrovirus in chronic fatigue syndrome and prostate cancer: reach for a scorecard, not a prescription pad. J. Infect. Dis. 202, 1463-1466.

Kim, S., Kim, N., Dong, B., Boren, D., Lee, S. A., Das, G. J., Gaughan, C., Klein, E. A., Lee, C., Silverman, R. H., and Chow, S.A. (2008). Integration site preference of xenotropic murine leukemia virusrelated virus, a new human retrovirus associated with prostate cancer. J. Virol. 82, 9964-9977.

Klein, S. L., and Calisher, C. H. (2007) Emergence and persistence of Hantaviruses. Curr. Top. Microbiol. Immunol. 315, 217-252.

Knouf, E. C., Metzger, M. J., Mitchell, P. S., Arroyo, J.D., Chevillet, J. R., Tewari, M. and Miller, A. D. (2009). Multiple integrated copies and high-level production of the human retrovirus XMRV (xenotropic murine leukemia virus-related virus) from $22 \mathrm{Rv} 1$ prostate carcinoma cells. J. Virol. 83, 7353-7356.

Kohler, G., and Milstein, C. (1975). Continuous cultures of fused cells secreting antibody of predefined specificity. Nature 256, 495-497.

Kunstman, K. J., Bhattacharya, T., Flaherty, J., Phair, J. P., and Wolinsky, S. M. (2010).Absence of xenotropic murine leukemia virus-related virus in blood cells of men at risk for and infected with HIV. AIDS 24, 1784-1785.

Kwon, D. N., Nguyen, S., Chew, A., Hsu, K., Greenhalgh, D., and Cho, K. (2008). Identification of putative endogenous retroviruses actively transcribed in the brain. Virus Genes 36, 439-447.

Liu, W., Worobey, M., Li, Y., Keele, B. F., Bibollet-Ruche, F., Guo, Y., Goepfert, P. A., Santiago, M. L., Ndjango, J. B., Neel, C., Clifford, S. L., Sanz, C., Kamenya, S., Wilson, M. L., Pusey, A. E., GrossCamp, N., Boesch, C., Smith, V., Zamma, K., Huffman, M. A., Mitani, J. C., Watts, D. P., Peeters, M., Shaw, G. M., Switzer, W. M., Sharp, P. M., and Hahn, B. H. (2008). Molecular ecology and natural history of simian foamy virus infection in wild-living chimpanzees. PLoS Pathog. 4, e1000097. doi: 10.1371/journal.ppat.1000097
Lo, S. C., Pripuzova, N., Li, B., Komaroff, A. L., Hung, G. C., Wang, R., and Alter, H. J. (2010). Detection of MLV-related virus gene sequences in blood of patients with chronic fatigue syndrome and healthy blood donors. Proc. Natl. Acad. Sci. U.S.A. 107, 15874-15879.

Lombardi, V. C., Ruscetti, F. W., Das, G. J., Pfost, M. A., Hagen, K. S., Peterson, D. L., Ruscetti, S. K., Bagni, R. K., Petrow-Sadowski, C., Gold, B., Dean M., Silverman, R. H., and Mikovits, J. A. (2009). Detection of an infectious retrovirus, XMRV, in blood cells of patients with chronic fatigue syndrome. Science 326, 585-589.

Maric, R., Pedersen, F. S., Kjeldbjerg, A., Moeller-Larsen, A., Bahrami, S., Brudek, T., Petersen, T., and Christensen, T. (2010). Absence of xenotropic murine leukaemia virusrelated virus in Danish patients with multiple sclerosis. J. Clin. Virol. 49, 227-228.

Marin, M., Tailor, C. S., Nouri, A., Kozak, S. L., and Kabat, D. (1999). Polymorphisms of the cell surface receptor control mouse susceptibilities to xenotropic and polytropic leukemia viruses. J. Virol. 73, 9362-9368.

Martinez-Fierro, M. L., Leach, R. J., Gomez-Guerra, L. S., GarzaGuajardo, R., Johnson-Pais, T., Beuten, J., Morales-Rodriguez, I. B., Hernandez-Ordonez, M. A., Calderon-Cardenas, G., OrtizLopez, R., Rivas-Estilla, A. M., ncerRodriguez, J., and Rojas-Martinez, A. (2010). Identification of viral infections in the prostate and evaluation of their association with cancer. $B M C$ Cancer 10, 326. doi: 10.1186/14712407-10-326

Miyazawa, T. (2010). Endogenous retroviruses as potential hazards for vaccines. Biologicals 38, 371-376.

Miyazawa, T., Yoshikawa, R., Golder, M., Okada, M., Stewart, H., and Palmarini, M. (2010). Isolation of an infectious endogenous retrovirus in a proportion of live attenuated vaccines for pets. $J$. Virol. 84, 3690-3694.

Murray, R. (1964). Biologicals for the control and therapy of virus diseases. Bacteriol. Rev. 28, 493-496.

Paprotka, T., Venkatachari, N. J., Chaipan, C., Burdick, R., Delviks-Frankenberry, K. A., Hu, W. S., and Pathak, V. K. (2010). Inhibition of xenotropic murine leukemia virus-related virus by APOBEC3 proteins and antiviral drugs. J. Virol. 84, 5719-5729.

Pastoret, P. P. (2010). Human and animal vaccine contaminations. Biologicals 38, 332-334.

Plotkin, S. A., and Wiktor, T. (1978). Rabies vaccination. Annu. Rev. Med. 29, 583-591. 
Portis, J. L., McAtee, F. J., and Hayes, S. F. (1987). Horizontal transmission of murine retroviruses. J. Virol. 61, 1037-1044.

Ribet, D., Harper, F., Esnault, C., Pierron, G., and Heidmann, T. (2008). The GLN family of murine endogenous retroviruses contains an element competent for infectious viral particle formation. J. Virol. 82, 4413-4419.

Sanjuan, R., Nebot, M. R., Chirico, N., Mansky, L. M., and Belshaw, R. (2010). Viral mutation rates. J. Virol. 84, 9733-9748.

Satterfield, B.C., Garcia, R. A., Gurrieri, F., and Schwartz, C. E. (2010). PCR and serology find no association between xenotropic murine leukemia virusrelated virus (XMRV) and autism. Mol. Autism 1, 14.

Sfanos, K. S., Sauvageot, J., Fedor, H. L., Dick, J.D., De Marzo, A. M., and Isaacs, W. B. (2008). A molecular analysis of prokaryotic and viral DNA sequences in prostate tissue from patients with prostate cancer indicates the presence of multiple and diverse microorganisms. Prostate 68, 306-320.

Sharma, P., Suppiah, S., Molinaro, R., Rogers, K., Das Gupta, J., Silverman, R., Hackett, J.Jr., Devare, S., Schochetman, G., and Villinger, F. (2010). “Organ and cell lineage dissemination of XMRV in rhesus macaques during acute and chronic infection [abstract]," in CROI, San Francisco, February 16-19, 2010, Paper \#150LB.

Silverman, R. H., Nguyen, C., Weight, C. J., and Klein, E. A. (2010). The human retrovirus XMRV in prostate cancer and chronic fatigue syndrome. Nat. Rev. Urol. 7, 392-402.

Sramkoski, R. M., Pretlow, T. G., Giaconia, J.M., Pretlow, T. P., Schwartz, S., Sy, M. S., Marengo, S. R., Rhim, J. S., Zhang, D., and Jacobberger, J. W. (1999). A new human prostate carcinoma cell line, 22Rv1. In Vitro Cell. Dev. Biol. Anim. 35, 403-409.

Stang, A., Petrasch-Parwez, E., Brandt, S., Dermietzel, R., Meyer, H. E., Stuhler, K., Liffers, S. T., Uberla, K., and Grunwald, T. (2009). Unintended spread of a biosafety level 2 recombinant retrovirus. Retrovirology 6, 86 . Stern, M., and Herrmann, R. (2005). Overview of monoclonal antibodies in cancer therapy: present and promise. Crit. Rev. Oncol. Hematol. 54, 11-29.

Stieler, K., Schulz, C., Lavanya, M., Aepfelbacher, M., Stocking, C., and Fischer, N. (2010). Host range and cellular tropism of the human exogenous Gammaretrovirus XMRV. Virology 399, 23-30.

Switzer, W. M., Bhullar, V., Shanmugam, V., Cong, M. E., Parekh, B., Lerche, N. W., Yee, J. L., Ely, J. J., Boneva, R., Chapman, L. E., Folks, T. M., and Heneine, W. (2004). Frequent simian foamy virus infection in persons occupationally exposed to nonhuman primates. J. Virol. 78, 2780-2789.

Switzer, W. M., Jia, H., Hohn, O., Zheng, H., Tang, S., Shankar, A., Bannert, N., Simmons, G., Hendry, R. M., Falkenberg, V. R., Reeves, W. C., and Heneine, W. (2010). Absence of evidence of xenotropic murine leukemia Virus-related virus infection in persons with chronic fatigue syndrome and healthy controls in the United States. Retrovirology 7, 57.

Tailor, C. S., Nouri, A., Lee, C. G., Kozak, C., and Kabat, D. (1999). Cloning and characterization of a cell surface receptor for xenotropic and polytropic murine leukemia viruses. Proc. Natl. Acad. Sci. U.S.A. 96, 927-932.

Takeuchi, Y., McClure, M. O., and Pizzato, M. (2008). Identification of
Gammaretroviruses constitutively released from cell lines used for human immunodeficiency virus research. J. Virol. 82, 12585-12588.

Trijzelaar, B. (1993). Regulatory affairs and biotechnology in Europe: III. Introduction into good regulatory practice-validation of virus removal and inactivation. Biotherapy 6, 93-102.

Urisman, A., Molinaro, R. J., Fischer, N., Plummer, S. J., Casey, G., Klein, E. A., Malathi, K., Magi-Galluzzi, C., Tubbs, R. R., Ganem, D., Silverman, R.H., and DeRisi, J. L. (2006). Identification of a novel Gammaretrovirus in prostate tumors of patients homozygous for R462Q RNASEL variant. PLoS Pathog. 2, e25. doi: 10.1371/journal. ppat.0020025

van der Kuyl, A. C., Dekker, J. T., and Goudsmit, J. (1999). Discovery of a new endogenous type $C$ retrovirus (FcEV) in cats: evidence for RD-114 being an FcEV(Gag-Pol)/baboon endogenous virus $\mathrm{BaEV}$ (Env) recombinant. J. Virol. 73, 7994-8002.

van Kuppeveld, F. J., de Jong, A. S., Lanke, K. H., Verhaegh, G. W., Melchers, W. J., Swanink, C. M., Bleijenberg, G., Netea, M. G., Galama, J. M., and van der Meer, J. W. (2010). Prevalence of xenotropic murine leukaemia virusrelated virus in patients with chronic fatigue syndrome in the Netherlands: retrospective analysis of samples from an established cohort. BMJ 340, c1018.

Verhaegh, G. W., de Jong, A. S., Smit, F. P., Jannink, S. A., Melchers, W. J., and Schalken, J. A. (2010). Prevalence of human xenotropic murine leukemia virus-related Gammaretrovirus (XMRV) in dutch prostate cancer patients. Prostate PMID: 20878949. [Epub ahead of print].
Weiss, R. A. (2010). A cautionary tale of virus and disease. BMC Biol. 8, 124. doi: 10.1186/1741-7007-8-124

Yan, Y., Liu, Q., Wollenberg, K., Martin, C., Buckler-White, A., and Kozak, C. A. (2010). Evolution of functional and sequence variants of the mammalian XPR1 receptor for mouse xenotropic Gammaretroviruses and the human-derived XMRV. J. Virol. 84, 11970-11980.

Yang, H., Bell, T. A., Churchill, G. A., and de Villena, F. P.-M. (2007). On the subspecific origin of the laboratory mouse. Nat. Genet. 39, 1100-1107.

Yoshikawa, R., Sato, E., Igarashi, T., and Miyazawa, T. (2010). Characterization of RD-114 virus isolated from a commercial canine vaccine manufactured using CRFK cells. J. Clin. Microbiol. 48, 3366-3369.

Conflict of Interest Statement: The authors declare that the research was conducted in the absence of any commercial or financial relationships that could be construed as a potential conflict of interest.

Received: 20 September 2010; accepted: 26 December 2010; published online: 17 January 2011.

Citation: van der Kuyl AC, Cornelissen M and Berkhout B (2011) Of mice and men: on the origin of XMRV. Front. Microbio. 1:147. doi: 10.3389/fmicb.2010.00147

This article was submitted to Frontiers in Virology, a specialty of Frontiers in Microbiology.

Copyright (C) 2011 van der Kuyl, Cornelissen and Berkhout. This is an open-access article subject to an exclusive license agreement between the authors and the Frontiers Research Foundation, which permits unrestricted use, distribution, and reproduction in any medium, provided the original authors and source are credited. 